Eur. J. Clin. Chem. Clin. Biochem.

Vol. 32,1994 , pp. $885-892$

(c) 1994 Walter de Gruyter \& Co. Berlin · New York

\title{
Purification of Isotransferrins by Concanavalin A Sepharose Chromatography and Preparative Isoelectric Focusing
}

\author{
By W. L. van Noort, G. de Jong and H. G. van Eijk \\ Department of Chemical Pathology, Erasmus University Rotterdam, Rotterdam, The Netherlands
}

(Received June 20/August 22, 1994)

Summary: 1. From pooled serum containing genetically homogeneous transferrin $C_{l}$, transferrin was purified and separated in three fractions (tri-tri-, bi-tri- and bi-bi-antennary transferrin $\mathrm{C}_{1}$ ), using Concanavalin A-Sepharose.

2. Each of these fractions was separated into its sialic acid-dependent subfractions by preparative isoelectric focusing. Sixteen iso-transferrin $C_{1}$ fractions were obtained, which differed in their degree of glycan branching and/or their sialic acid content.

3. Preliminary carbohydrate analyses suggest that in some iso-transferrins the $\mathrm{N}$-acetylglucosamine and the galactose content is lower than expected.

\section{Introduction}

The main function of transferrin is the transport of iron between the sites of absorption and storage and the sites of utilization such as myoglobin and haemoglobin synthesis $(1-5)$.

Transferrin is an $M_{\mathrm{r}} 80000$ monomeric glycoprotein containing two branched oligosaccharide chains, N-glycosidically attached to asparagine residues in the carboxyl-terminal domain $(1-5)$.

A series of papers on the composition analysis of transferrin glycans has been published in the past fifteen years $(6-14)$. Recently we published the sugar analyses of fractions of genetically homogeneous transferrin $C_{1}$, obtained by preparative isoelectric focusing in immobilized $\mathrm{pH}$ gradients, which produces fractions containing different amounts of sialic acid (15). These methods were optimized for the preparation of subfractions. Separation on Concanavalin A Sepharose (16) resulted in fractions with glycans carrying the same number of antennae.

Using preparative isoelectric focusing in ultra-thin Immobiline gels (15) each tri-tri-, bi-tri- and bi-bi-antennary $\mathrm{Fe}_{2}$ transferrin fraction was fractionated into 5-6 fractions that differed in their number of sialic acid residues. Thus, sixteen different iso-transferrins were available for study.

Several authors have recently remarked on the desirability of analysing thoroughly purified fractions (1721 ), for the investigation of different pathologies, including transferrin analysis in alcoholism $(20,21)$, and the analysis of other glycoproteins, e.g. in cancer $(18,19)$.

\section{Materials and Methods}

Preparation of transferrin subfractions

Identification of serum containing transferrin $C_{l}$

Sera were obtained from adult healthy volunteers and checked for $C_{1}$ transferrin genetic homogeneity as follows:

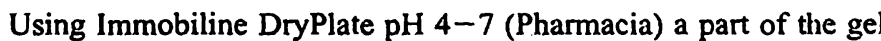
was cut out to the same size as Phast Gel, to obtain a pH-gradient between the electrodes of 5.0-6.0. This piece of DryPlate was rehydrated by overlaying it with $1 \mathrm{ml} 170 \mathrm{~g} / 1$ glycerol for 2-3 hours. Serum $(50 \mu \mathrm{ll})$ was mixed with $2 \mu \mathrm{l} 0.5 \mathrm{~mol} / 1 \mathrm{NaHCO}_{3}$ and 2 ul $10 \mathrm{mmol} / \mathrm{h} \mathrm{Fe}(\mathrm{III})$ citrate.

Using PhastSystem (Pharmacia), the Inmobiline gel was run with $0.3 \mu \mathrm{l}$ of twelve different sera, using the program: 
Sample application down at Sample application up at

Extra alarm at

Sep. x.1: $2000 \mathrm{~V}$

Sep. x.2: $200 \mathrm{~V}$

Sep. x.3: $2000 \mathrm{~V}$
$2.0 \mathrm{~mA}$

$0.3 \mathrm{~mA}$

$2.0 \mathrm{~mA}$ x.2,

x.3,

$15^{\circ} \mathrm{C}$

$0 \mathrm{Vh}$.

$0 \mathrm{Vh}$.

$350 \mathrm{Vh}$.

$485 \mathrm{Vh}$.

$15 \mathrm{Vh}$.

$1300 \mathrm{Vh}$.
Prefocusing was necessary to obtain sharp bands without smears.

Paraffin oil $(50 \mu \mathrm{l})$ was applied between the cooling plate and gel backing.

At the end of the run the gel was incubated with $100 \mu \mathrm{l}$ antitransferrin solution (Dako-immunoglobulins, Denmark) for 15-30 minutes at room temperature.

The gel was washed overnight in saline (with several changes), incubated with $200 \mathrm{~g} / 1$ trichloroacetic acid and stained with Coomassie Brilliant Blue R-250 $1 \mathrm{~g} / \mathrm{l}$ at $50^{\circ} \mathrm{C}$ for 10 minutes as described in the PhastSystem users Manual (Pharmacia), and destained at $20^{\circ} \mathrm{C}$.

As transferrin $C_{1}$ is the commonly occurring variant (70-80\%), other variants are easily recognized by comparing 12 sera on one gel, and can then be excluded from the purification.

\section{Isolation of transferrin from serum}

The transferrin $C_{1}$ (all transferrin used in this paper is from the same source) was isolated from the serum as described earlier (22) by immuno affinity chromatography.

A specific anti human transferrin Sepharose column was used. Attention must be paid to a complete removal of all other serum proteins that elute with the first buffer overnight.

\section{Separation of transferrin fractions differing in their degree of gly- can branching}

The transferrin $C_{1}$ obtained from step 2 was separated in a fraction with two triantennary glycans (further called tri-tri-transferrin $C_{1}$ ), a fraction with one bi-antennary and one tri-antennary glycan (further called bi-tri-transferrin $C_{1}$ ) and a fraction with two bi-antennary glycans (further called bi-bi-transferrin $C_{1}$ ) by Concanavalin A Sepharose chromatography as described by Hatton \& Berry (16).

\section{Separation of transferrin subfractions}

Each fraction was further separated into fractions with different sialic acid contents, by preparative isoelectric focusing, using Immobiline DryPlate pH 5.0-6.0 on a Multiphor (Pharmacia, Upsala, Sweden) as described previously (15). This method depends on the stable pI-gradient, the high loading capacity and the high resolving power of Immobiline gel. Large amounts of protein become exuded from the gel as concentrated droplets of protein solution. Small amounts of protein can be obtained by diffusion after cutting out pieces of gel containing the appropriate bands with scissors.

\section{Analyses}

\section{Densitometry}

Densitometric scans of purified iso-transferrin fractions were performed using Ultroscan XL (He/Nelaser, $\lambda=633 \mathrm{~nm}$, Pharmacia, Sweden).

\section{Check of subfraction homogeneity}

The sialic acid-dependent subfractions were checked for homogeneity by isoelectric focusing using PhastGels IEF pH 4-6:5, as recently described (23).

\section{Desialylation}

Neuraminidase from $\mathrm{Cl}$. perfringens, type $\mathrm{V}$ from Sigma was used: 4 Units were dissolved in $1 \mathrm{ml} 0.1 \mathrm{~mol} / 1$ sodium acetate, $\mathrm{pH}$. An aliquot $(50 \mu \mathrm{l})$ of this solution was mixed with $5 \mu \mathrm{l}$ transferrin preparation $(0.5-1 \mathrm{~g} / \mathrm{l})$ and incubated for 72 hours at $4^{\circ} \mathrm{C}$.

The $\mathrm{pH}$ was then raised to 8 using $2 \mu \mathrm{l} 0.5 \mathrm{~mol} / 1 \mathrm{NaHCO}_{3}$, and $1 \mathrm{Hl} 10 \mathrm{mmol} / \mathrm{Fe}$ (III)citrate was added for iron saturation.

After two hours, the samples were analysed using PhastGel IEF 4-6.5 (see above).

\section{Analysis of $N$-acetylglucosamine and amino acids}

\section{a) Hydrolysis and sample preparation}

An adaptation of the previously described method employing $3 \mathrm{~mol} / \mathrm{l} p$-toluene sulphonic acid for hydrolysis was used (24).

Protein solution $(50 \mu \mathrm{l}$ containing $0.5-1 \mathrm{~g} / \mathrm{l}$ protein and $10 \mathrm{mmol} / \mathrm{l}$ $\mathrm{NaHCO}_{3}$ ) was mixed with $150 \mu \mathrm{l}$ of a $4 \mathrm{~mol} / \mathrm{l} p$-toluene sulphonic acid solution. The mixture was degassed at $<1 \mathrm{~mm} \mathrm{Hg}$, sealed and incubated at $110^{\circ} \mathrm{C}$ for 24 hours.

The hydrolysate was titrated with $1 \mathrm{~mol} / 1 \mathrm{NaOH}$ to $\mathrm{pH} 2.00 \pm 0.02$.

After filtration over a $0.45 \mu \mathrm{m}$ disk filter (Millipore, Japan) 25 or $50 \mu \mathrm{l}$ were analysed using an ALPHA PLUS 4151 amino acid analyser (Pharmacia/LKB/Biochrom-Cambridge, England).

\section{b) Analysis}

The column eluate $(21 \mathrm{ml} / \mathrm{h})$ was mixed with $o$-phthalaldehyde reagent $(8 \mathrm{ml} / \mathrm{h})$, prepared according to the apparatus Handbook, except that the volume of $\beta$-mercaptoethanol was doubled (all chemicals from Merck, Germany).

The T-piece in which eluate and reagent are mixed, was connected directly with a fluorimeter (F1000, Hitachi). The excitation wavelength was set at $340 \mathrm{~nm}$ and the emission wavelength at $455 \mathrm{~nm}$. The fluorimeter outlet was connected with a standard photometer (coil temperature: $50^{\circ} \mathrm{C}$ ) to generate some back-pressure but the back-pressure valve spring was removed to avoid the back-pressure becoming too high. The fluorimeter signal was received and stored by a peak-integrator (Chromato-Integrator D2000, Hitachi).

\section{The analysis of hexoses}

We have already described this method extensively (25). After hydrolysis with $2 \mathrm{~mol} / \mathrm{l}$ trifluoroacetic acid for 16 hours at $100^{\circ} \mathrm{C}$ and $<1 \mathrm{~mm} \mathrm{Hg}$, analyses are performed in the subnanomole range using an adapted amino acid analyser.

Partition chromatography was used, and the eluate was mixed with tetrazolium blue chloride (Fluka Chemie, Belgium - cat. No. 88190 ) in $0.18 \mathrm{~mol} / \mathrm{l} \mathrm{NaOH}$. The reaction product was detected at $570 \mathrm{~nm}$ and the signal was stored by the same integrator as used for the amino acid analyses.

\section{Results}

\section{Purification of sixteen different transferrin} $\mathrm{C}_{1}$ fractions

Transferrin subfractions were obtained according to the scheme of figure 1.

Figure 2 shows a typical example of the genetic homogeneity of twelve normal serai of healthy adult volun- 
I. Pooled serum ( genetically homogeneous), $100 \mathrm{ml}$

Transferrin $\mathrm{C}_{1}, \pm 300 \mathrm{mg}$

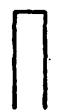

II. Immunoaffinity purification ( 22 )<smiles>C=CCCCC</smiles>

Transferrin $C_{1}, \pm 250 \mathrm{mg}$

Tri-tri-antennary transferrin $C_{1}$ $5 \mathrm{mg}$
Bi-tri-antennary Transferrin $C_{1}$

$50 \mathrm{mg}$<smiles>CCCC</smiles>

IV. Preparative isvelectric focusing ( 15)<smiles>C=CCCCC</smiles>

3-,4-,5-,6- \& 7- SialoTri-tri-antennary transferrin $C_{1}$
2-,3-,4-,5-,6- \& 7- SialoBi-tri-antennary transferrin $\mathrm{C}_{1}$
Bi-bi-antennary transferrin $C_{1}$

$150 \mathrm{mg}$

Fig. 1 Outline of the main techniques and the essential results of the sialo-transferrin preparations $(22,16,15)$.

teers. While eight lanes show the same pattern of microheterogeneity, sera in lanes $a, c, f$ and $k$ show an apparently abnormal pattern. Due to diallelic expression of the transferrin gene, the normal pattern and the pattern

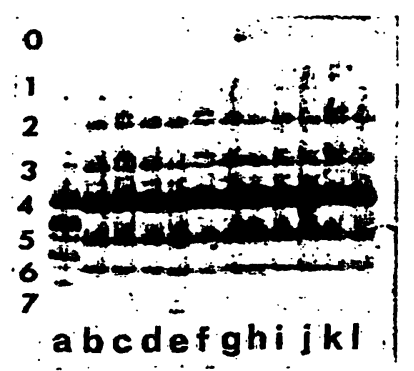

Fig. 2 On high resolution Immobiline gels, twelve different sera show eight patterns with the common occurring transferrin $C_{1}$ variant $(70 \%)$. The four deviating patterns (in the lanes $a, c, f$, and $k$ ) are easy to recognize. of the variant gene product co-exist, thus duplicating the number of bands without an actual change in the microheterogeneity pattern.

Figure 3 shows the densitometric scans of the transferrin $\mathrm{C}_{1}$ obtained directly after separation using an antitransferrin column (22), and the three fractions that were obtained after separation of the purified transferrin by Concanavalin A Sepharose: i.e. tri-tri-antennary transferrin $C_{1}$, bi-tri-antennary transferrin $C_{1}$, and bi-biantennary transferrin $C_{1}(16)$. Although each fraction is homogeneous with respect to their branching, they all contain at least five sialo-transferrin fractions (see the figures 5-7 and table 1).

This sialic acid-dependent heterogeneity is confirmed in figure 4, in which similar fractions are seen in lanes $g$, $e$ and $a$. Lanes $b$ and $c$ show a partial desialylation of 


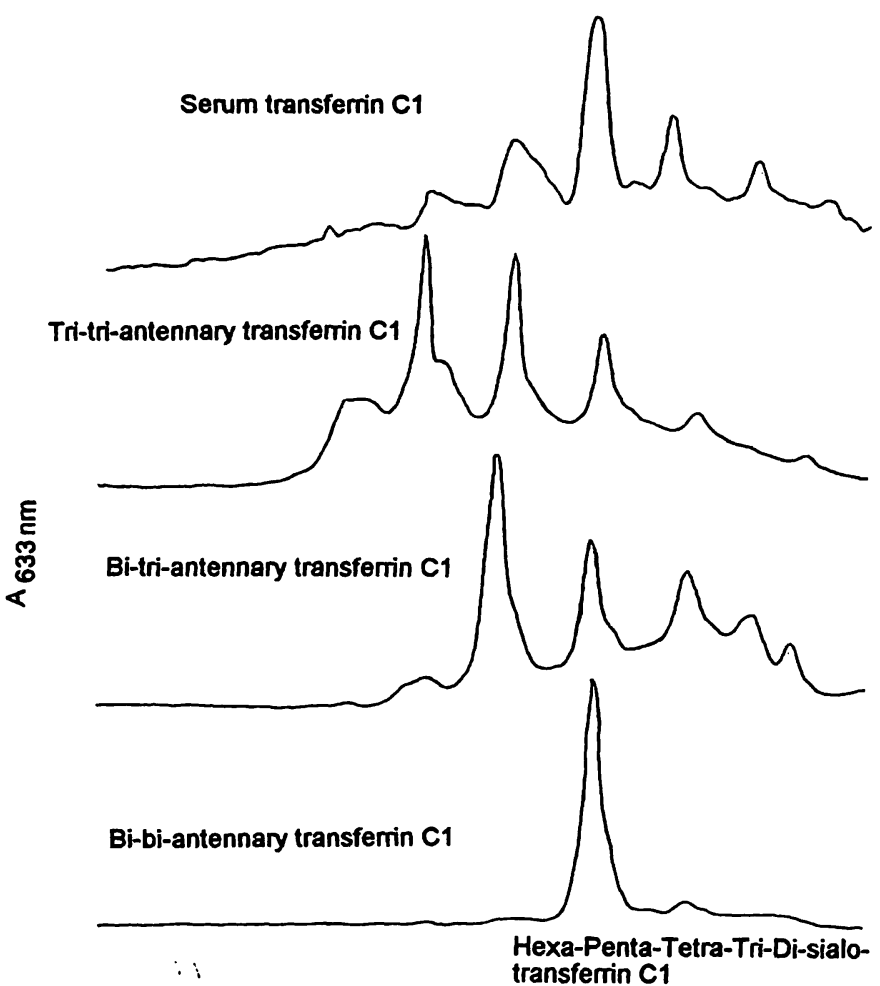

Fig. 3 Densitometric scans of the unfractionated purified transferrin (top) and the three transferrin fractions obtained after Concanavalin A Sepharose separation $(10,16,23)$.

the bi-bi-transferrin $\mathrm{C}_{1}$, while lanes $\mathrm{d}, \mathrm{f}$ and $\mathrm{h}$ show the asialo variants of bi-bi-transferrin $\mathrm{C}_{1}$, bi-tri-transferrin $\mathrm{C}_{1}$, and tri-tri-transferrin $\mathrm{C}_{1}$, respectively. Prolonged exposure to neuraminidase abolished all variability in each fraction, leaving behind only the asialo-transferrin in all fractions, confirming that microheterogeneity is the cause of the electrophoretic diversity in all fractions.

The three fractions from the Concanavalin A-Sepharose separation were each separated into their sialic acid-dependent fractions and isolated by preparative isoelectric focusing on ultra thin Immobiline gels (Pharmacia) as described recently (15).

Figure 5 shows the fractions obtained from tri-tri-antennary transferrin $C_{1}$, ranging from 3-sialo-tri-tri-antennary transferrin $C_{1}$ to the 7-sialo-tri-tri-antennary transferrin $C_{1}$ in lanes $a-e$, while in lanes $f-h$ contain 4-sialo-bi-bi-antennary preparations for comparison.

Although we only obtained less than .one milligram of most of the subfractions from $100 \mathrm{ml}$ of serum, we were able to analyse both their amino acid and their carbohydrate composition.

Figure 6 shows the purification products of the bi-triantennary transferrin $C_{1}$, ranging from 2-sialo-bi-tri-antennary transferrin $C_{1}$ to 7-sialo-bi-tri-antennary transferrin $C_{1}$ in lanes $a-f$, while lanes $g$ and $h$ contain a 4-sialo-bi-bi-transferrin $C_{1}$ as reference. A similar display of bi-bi-antennary transferrin $C_{1}$ sialo-variants is found in figure 7 , lanes a-e, respectively, with 4-sialotransferrin $C_{l}$ references in lanes $f-h$.

As mentioned already by Hatton \& Berry (16), serum transferrin contains about $4 \%$ tri-tri-antennary transferrin and about $18 \%$ bi-tri-antennary transferrin. Consequently less starting material could be applied in the purification of tri-tri-transferrin $\mathrm{C}_{1}$ sialo-variants. As a result, minor contamination of subfractions are seen as vicinal bands in bi-bi- and bi-tri-antennary transferrin preparations, albeit at negligible amounts.

\section{Results of the sugar analyses of the transferrin fractions}

Table 1 summarizes the results for $\mathrm{N}$-acetylglucosamine, galactose and fucose.

According to 1. c. (29-31) a glycan can bear an additional sialic acid and/or an additional $\mathrm{N}$-acetylglucosamine as visualized in figure 8 . It is therefore possible for 5- and 6-sialo transferrin to occur, although there are only two antennae on each glycan. The galactose values

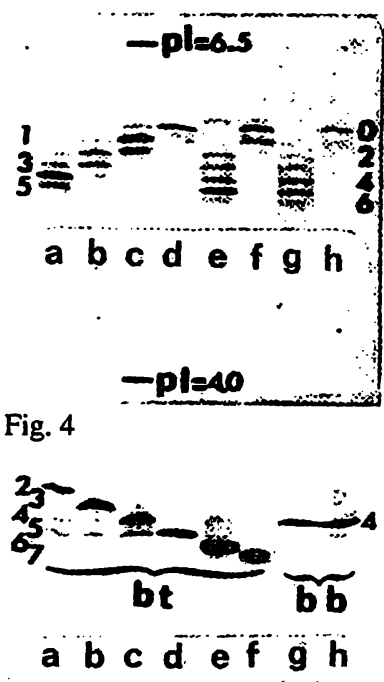

Fig. 6

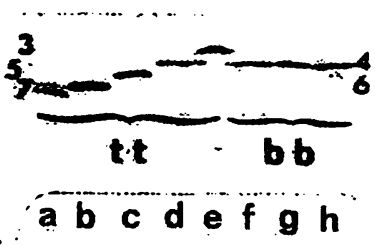

Fig. 5
Fig. 4 PhastGel electrophoresis of the three transferrin fractions. Lanes a, e and $g$ contain a bi-bi-transferrin $C_{1}$, a bi-tri-transferrin $C_{1}$, and a tri-tri-transferrin $C_{1}$ preparation, respectively.

Lanes $b$ and $c$ show partially desialylated bi-bi-transferrin $C_{1}$. Lanes $d, f$ and $h$ show the completely desialylated products of the preparations in lanes a, e and $g$, respectively, all resulting in the same asialo-transferrin $C_{1}$ band (23) (asialo band at the right hand top-side of the gel).

Fig. 5 PhastGel electrophoresis of tri-tri-transferrins. Lanes a-e contain the 7-, 6-, 5-, 4- and 3-sialo-tri-tri-transferrin $C_{1}$ fractions, respectively, as obtained by preparative isoelectric focusing (15). Lanes $f-h$ contain 4-sialo-bi-bi-transferrin $C_{1}$ as a reference.

Fig. 6 PhastGel electrophoresis of bi-tri-transferrins. Lanes $a-f$ contain the 2-, 3-, 4-, 5-, 6- and 7-sialo-transferrin $C_{1}$. Lanes $g$ and $h$ contain two 4-sialo-bi-bi-transferrin $C_{1}$ fractions for reference $(15,23)$.

Fig. 7 PhastGel electrophoresis of bi-bi-transferrins. Five fractions were analysed (lanes $a-e)$. Standards of 4-sialo-bi-bitransferrin $\mathrm{C}_{1}$ (lanes $\mathrm{f}-\mathrm{g}$ ) $(15,23)$. - : 
Tab. 1 Values of galactose and $\mathrm{N}$-acutylglucosamine expressed in moles sugar/mole protein for the sixteen purified fractions of human serum transfierrin.

Calculated percentage occurrences of each fraction in normal human serum are also given. These expected values are based on the types of branching: tri-tri-. bi-tri- and bi-bi-transferrin $C_{1}$ according to $1 . c$. (16) and on the recovery of sialo-transferrins after preparative isoelectric focusing purification (15). Of the three fractions of the Concanavalin A separation the fucose content is noted. The expected values agree with the literature (16).

\begin{tabular}{|c|c|c|c|c|c|c|c|c|c|}
\hline \multirow{2}{*}{$\begin{array}{l}\text { Sialylation degree of } \\
\text { transferrin } C_{1}\end{array}$} & \multicolumn{3}{|c|}{ tri-tri-transferrin $C_{1}$} & \multicolumn{3}{|c|}{ bi-tri-transferrin $C_{1}$} & \multicolumn{3}{|c|}{ bi-bi-transferrin $C_{1}$} \\
\hline & GlcNH $_{2}$ & Gal & $\%$ & $\mathrm{GlcNH}_{2}$ & Gal & $\%$ & $\mathrm{GlcNH}_{2}$ & Gal & $\%$ \\
\hline $\begin{array}{l}\text { disialylation of degrec } \\
\text { transferrin } C_{1}\end{array}$ & - & - & $<1$ & 5.3 & 4.4 & 2 & 7.4 & 4.1 & $<1$ \\
\hline $\begin{array}{l}\text { trisialylation degree of } \\
\text { transferrin } C_{1}\end{array}$ & 8.1 & 5.6 & $<1$ & 7.5 & 4.8 & 3 & 7.4 & 4.0 & 6 \\
\hline $\begin{array}{l}\text { tetrasialylation degree of } \\
\text { transferrin } C_{1}\end{array}$ & 8.0 & 5.7 & $<1$ & 8.2 & 5.1 & 4 & 8.0 & 4.1 & 65 \\
\hline $\begin{array}{l}\text { pentasialylation degree of } \\
\text { transferrin } C_{1}\end{array}$ & 8.7 & 5.7 & $<1$ & 9.0 & 5.0 & 5 & 7.7 & 4.2 & 6 \\
\hline $\begin{array}{l}\text { hexasialylation degrec of } \\
\text { transferrin } C_{1}\end{array}$ & $\mathbf{x}$ & 5.5 & 3 & 8.8 & 5.2 & 1 & 8.8 & 4.1 & 1 \\
\hline $\begin{array}{l}\text { heptasialylation degree of } \\
\text { transferrin } C_{1}\end{array}$ & 7.4 & $x$ & $<1$ & 7.8 & 4.3 & $<1$ & - & $<1$ & \\
\hline Expected (16) & 10 & 6 & 4 & 9 & 5 & 18 & 8 & 4 & 78 \\
\hline Fucose & & 0.6 & & & 0.4 & & & 0.1 & \\
\hline
\end{tabular}

$\%$ the calculated percentage occurrences of this variant in normal serum is given.

- not detectable

$x$ not available for this analysis

$\mathrm{GlcNH}_{2}=$ glucosamine

$\mathrm{Gal}=$ galactose

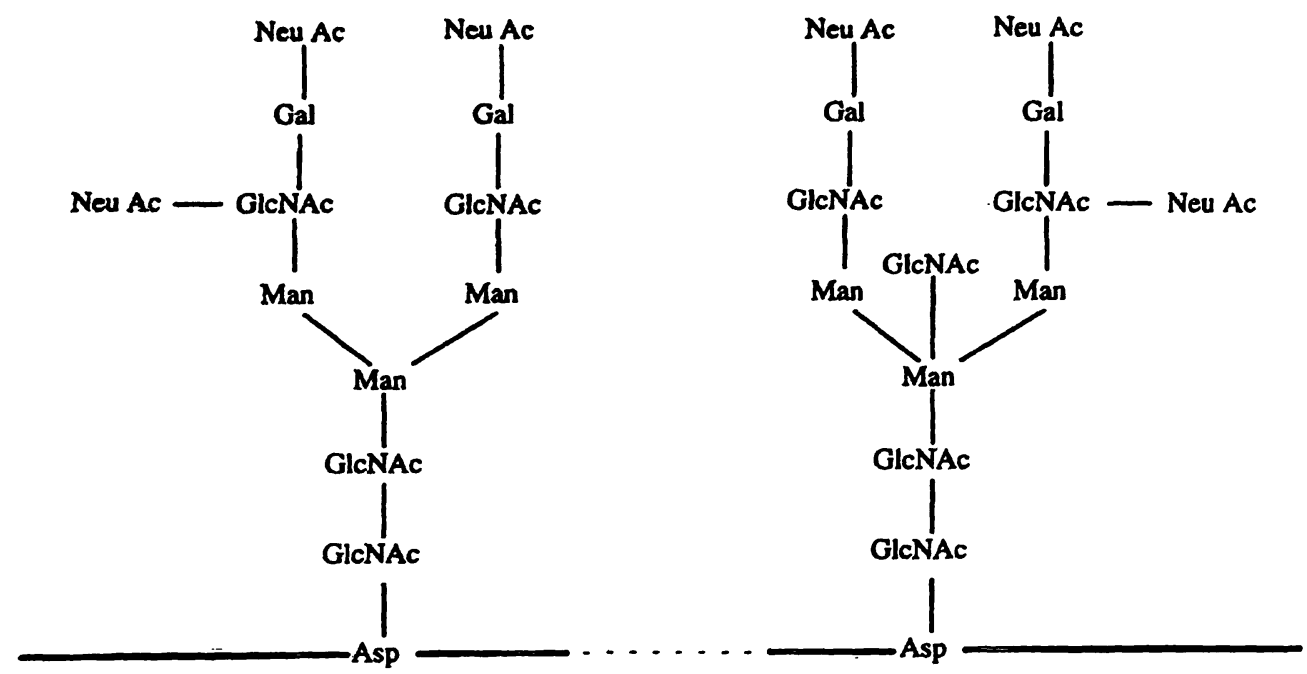

Fig. 8 The two presumed glycan structures of the 6-sialo-bi-bitransferrin $C_{1}$ isotransferrin containing two additional sialic acids and an additional $\mathrm{N}$-acetylglucosamine (see tab. 1), derived according to 1.c. $(29-31)$. in most fractions are near to the expected values (see tab. 1) although in particular the 2- and 2-sialo-bi-tritransferrin $C_{1}$ fractions seem to contain less galactose than expected.

The $\mathrm{N}$-acetylglucosamine values are lower than expected, in particular in bi-tri- and tri-tri-transferrin $\mathrm{C}_{1}$ fractions.

However, when the calculated percentage occurrences of each fraction in serum are taken into account, it ap- pears that about $75 \%$ of all transferrin variants contain the expected number of $\mathrm{N}$-acetylglucosamines. The content of fucose was determined in each of the sixteen fractions. In table 1 they are only specified according to the antennae-dependent fractions. Yet, it is very clear that transferrin fractions that are more branched apparently contain more fucose. This may be related to the fact that in transferrins isolated from diseased persons both the branching of glycoproteins and the fucose content (predominantly in cancer) are much higher than 
in normals (26), but at the moment we cannot confirm this finding.

\section{Amino acid determination}

Table 2 shows the results of the amino acid analyses, in which the $\mathrm{N}$-acetylglucosamine values were also obtained (see tab. 1). Within the margins of error, the results indicate that all fractions show the same amino acid composition (24).

\section{Discussion}

Electrophoretic mobility of transferrin is known to be influenced by genetically determined differences in amino acid content, as well as differences in iron content, sialic acid content and the number of glycan antennae. The interpretation of the patterns has been extensively reviewed $(1-5)$.

Theoretically, if partially Fe-saturated, genetically pure transferrin $C_{1} C_{2}$ is focused on an Immobiline gel, this would result in the separation of 72 variants (fig. 9), illustrating the wide heterogeneity of transferrin variants that must exist in one individual serum (4). For our investigation we halved this number by selecting only genetically homogeneous transferrin, transferrin $C_{1}$. To further simplify the pattern, we limited the number of fractions by a factor 4 using only fully iron-saturated transferrin $(15,23,27)$ (fig. 9b). Applying Concanavalin A Sepharose we distinguished not only the various sialotransferrins, but also the three transferrin forms which differ in their glycan branching, tri-tri-, bi-tri- and bi-bi-

Tab. 2 Average values from the amino acid analyses of the five or six sialo-transferrin fractions of each Concanavalin A fraction. In the far right column (seq. anal. 33) the values of the sequence analyses obtained from l. c. (33) are given.

\begin{tabular}{|c|c|c|c|c|}
\hline \multirow[t]{2}{*}{ Amino acids } & \multicolumn{3}{|c|}{$\begin{array}{l}\text { Concanavalin A } \\
\text { transferrin fractions }\end{array}$} & \multirow{2}{*}{$\begin{array}{l}\text { Reference } \\
\text { values } \\
\text { Sequence } \\
\text { analyses (33) }\end{array}$} \\
\hline & $\begin{array}{l}\text { bi-bi- } \\
\bar{x}\end{array}$ & $\begin{array}{l}\text { bi-tri- } \\
\dot{\bar{x}}\end{array}$ & $\begin{array}{l}\text { tri-tri- } \\
x\end{array}$ & \\
\hline Asx & 79 & 78 & 78 & 79 \\
\hline Thr & 31 & 29 & 29 & 30 \\
\hline Ser & 41 & 43 & 44 & 41 \\
\hline Glx & 59 & 58 & 60 & 59 \\
\hline Gly & 49 & 50 & 54 & 50 \\
\hline Ala & 57 & 59 & 58 & 57 \\
\hline Val & 46 & 45 & 45 & 45 \\
\hline Met & 9 & 9 & 8 & 9 \\
\hline Ile & 15 & 17 & 18 & 15 \\
\hline Leu & 58 & 58 & 56 & 58 \\
\hline Tyr & 27 & 26 & 24 & 26 \\
\hline Phe & 28 & 28 & 27 & 28 \\
\hline Lys & 56 & 58 & 56 & 58 \\
\hline His & 19 & 19 & 18 & 19 \\
\hline Arg & 26 & 26 & 26 & 26 \\
\hline
\end{tabular}

transferrin $C_{1}$ (16). Figure 3 shows that each of these three forms from fresh serum can be further fractionated according to the types of sialo-transferrins. The number of terminal sialic acids contributes to the differences in isoelectric point, irrespective of the number of antennae, which is confirmed in figure $4 .{ }^{\prime}$

The conclusions that can be drawn from the results of table 1 are that all of the sixteen analysed fractions differ either in sialic acid content (see figures 3-7), in the number of antennae (with consequent structural differences in both $\mathrm{N}$-acetylglucosamine, galactose and sialic acid content), or in fucose content.

In some variants the content of $\mathrm{N}$-acetylglucosamine or galactose or both is less than that calculated for model glycans that would be expected to migrate to these positions, based on our present knowledge of glycan structure. As sialic acid can also be bound to the $\mathrm{N}$-acetylglucosamine, instead of galactose, 5- and 6-sialo-bi-bitransferrin $\mathrm{C}_{1}$ may occur. An additional $\mathrm{N}$-acetylglucosamine of the 6-sialo-bi-bi-transferrin $\mathrm{C}_{1}$ can be bound to the central mannose $(29-31)$, which may explain these differences.

Figure 8 shows the presumed glycan structures of the latter iso-transferrin.

Several authors have reported changes in the (percentual) sialo-transferrin distribution in various diseases as well as during pregnancy $(4,5,13,23,28)$.

Despite their analytical accuracies, these results leave room for interpretation. One might suppose that in haemochromatosis, 5- and 6-siälo-bi-tri-transferrin variants are elevated, while in rheumatoid arthritis the 5-, 6and 7-sialo-tri-tri-transferrin fractions could be increased. Results presented in this paper demonstrate that it is possible to find subtle differences in the various transferrin subfractions, which may provide additional valuable information concerning glycan structures.

This is important, because the terminal sugar of even only one of the four to six antennae might influence the properties of the glycoprotein $(7,17,18,32)$. By combining the data of our sugar analyses (tab. 1) and the published structures of glycans (29-31), it is possible to derive interesting abnormal structures. These differences can be determined by analysis of the sialo-transferrins distribution in conjunction with crossed affinity isoelectric focusing, a method which we are developing for transferrin.

\section{Conclusion}

By applying the set of techniquess presented in this paper it is possible to obtain a sufficient quantity of each of 


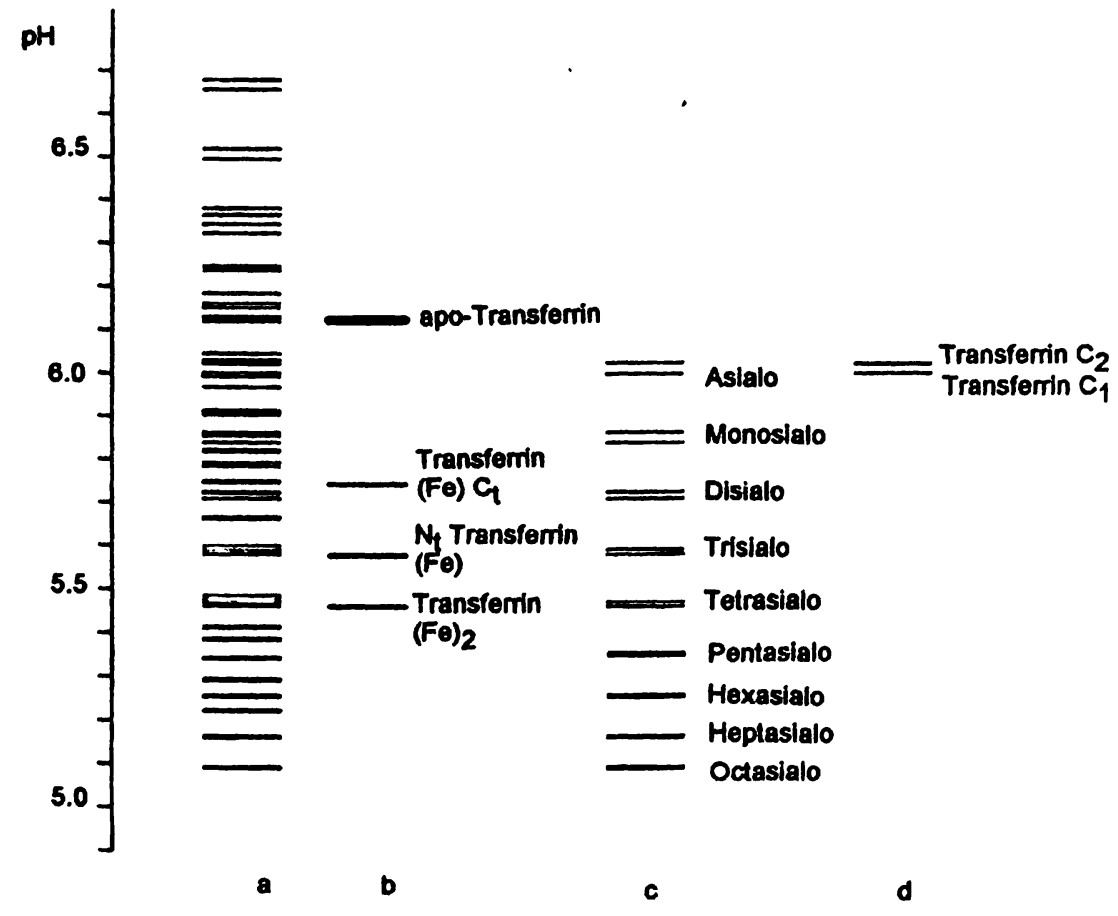

Fig. 9 Diagrammatic representation of transferrin microheterogeneity of an individual with the $C_{1} C_{2}$ genotype detectable on IEF. a) Total number of bands that can theoretically be distinguished on an Immobiline gel (4).

b) Major iron-dependent bands as revealed by IEF in carrier ampholyte (Ampholine) gels (23).

the sixteen purified isotransferrins to quantify their specific set of carbohydrates, even though the purification started from only $100 \mathrm{ml}$ serum. Serum of individuals c) Microheterogeneous forms of transferrin that can be separated from iron-saturated transferrin (15).

d) Reduction of the number of bands from 72 (a) to 2 by ironsaturation and neuraminidase treatment of the transferrin, a procedure that can be useful in the assessment of genotypic variations (sce fig. 4).

(Modified after 1.c. (4) with permission.)

with genetically homogeneous transferrin is required for optimal results.

\section{References}

1. Aisen, P. \& Listowsky, I. (1980) Iron transport and storage proteins. Ann. Rev. Biochem. 49, 357-393.

2. Brock, J. H. (1985) In: The Transferrins, Metalloproteins (Harrison, P. M., ed.) Verlag Chemie, Weinheim, pp. 183-261.

3. Welch, S. (1992) In: Transferrin: The Iron Carrier, Human Transferrin, CRC Press, Florida, U. S. A., pp. 253-274.

4. de Jong, G. \& van Eijk, H. G. (1988) Microheterogeneity of human serum transferrin: A biological phenomenon studied by isoelectric focusing in immobilized $\mathrm{pH}$ gradients. Electrophoresis $9,589-598$.

5. de Jong, G., van Noort, W. L., Feelders, R. A., de Jeu-Jaspars, C. M. H. \& van Eijk, H. G. (1992) Adaptation of transferrin protein and glycan synthesis. Clin. Chim: Acta 212, 27-45.

6. Wong, K.-L. \& Regoeczi, E. (1977) The molecular components of human transferrin type C. Int. J. Peptide Protein Res. 9, 241-248.

7. Hatton, M. W. C., März, L., Berry, L. R., Debanne, M. T. \& Regoeczi, E. (1979) Bi- and tri-antennary human transferrin glycopeptides and their affinities for the hepatic lectin specific for asialoglycoproteins. Biochem. J. 181, 633-638.

8. Barr, J. \& Nordin, P. (1980) Microdetermination of neutral and amino sugars found in glycoproteins. Anal. Biochem. 108, 313-31.9.

9. Chaplin, M. F. (1982) A rapid and sensitive method for the analysis of carbohydrate components in glycoproteins using gas-liquid chromatography. Anal. Biochem. 123, 336-341.
10. Kerckaert, J.-P. \& Bayard, B. (1982) Glycan uniformity within molecular variants of transferrin with distinct affinity for Concanavalin A. Biochem. Biophys. Res. Comm. 105, 10231030.

11. Takemoto, H., Hase, S. \& Ikenaka, T. (1985) Microquantitative analysis of neutral and amino sugars as fluorescent pyridylamino derivatives by high-performance liquid chromatography. Anal. Biochem. 145, 245-250.

12. Honda, S., Akao, E., Suzuki, S., Okuda, M., Kakehi, K. \& Nakamura, J. (1989) High-performance liquid chromatography of reducing carbohydrates as strongly ultraviolet-absorbing and electrochemically sensitive 1-phenyl-3-methyl-5-pyrazolone derivatives. Anal. Biochem. 180, 351-357.

13. Stibler, H. \& Jaeken, J. (1990) Carbohydrate deficient serum transferrin in a new systemic hereditary syndrome. Arch. Dis. Childhood 65, 107-111.

14. Ogawa, H., Ueno, M., Uchibori, H., Matsumoto, I. \& Seno, N. (1990) Direct carbohydrate analysis of glycoproteins electroblotted onto polyvinylidene difluoride membrane from medium dodecyl sulfate polyacrylamide gel. Anal. Biochem. $190,165-169$.

15. de Jong, G., van Noort, W. L. \& van Eijk, H. G. (1992) Carbohydrate analysis of transferrin subfractions isolated by preparative isoelectric focusing in immobilized $\mathrm{pH}$ gradients. Electrophoresis $13,225-228$. 
16. Hatton, M. W. C. \& Berry, L. R. (1984) Location of bi- and tri-antennary $\mathrm{N}$-glycans among the heterogeneous forms of human serum transferrin: A topographical study. Biochem. Soc. Transactions 12, 293-294.

17. Rademacher, T. W., Parekh, R. B. \& Dwek, R. A. (1988) Glycobiology. Ann. Rev. Biochem. 57, 785-838.

18. Taketa, K. \& Hirai, H. (1989) Lectin affinity electrophoresis of $\alpha$-fetoprotein in cancer diagnosis. Electrophoresis 10, 562-567.

19. Hansen, J. E. S., Bog-Hansen, T. C., Pedersen, B. \& Neland, K. (1989) Microheterogeneity of orosomucoid in pathological conditions. Electrophoresis 10, 574-578.

20. Stibler, H. \& Borg, S. (1986) Carbohydrate composition of serum transferrin in alcoholic patients. Alcoholism: Clin. Exp. Res. 10, 61-64.

21. Heegaard, N. H. H., Hagerup, M., Thomsen, A. C. \& Heegaard, P. M. H. (1989) Concanavalin A crossed affinity immunoelectrophoresis and image analysis for semiquantitative evaluation of microheterogeneity profiles of human serum transferrin from alcoholics and normal individuals. Electrophoresis 10,836-840.

22. van Eijk, H. G. \& van Noort, W. L. (1976) Isolation of rat transferrin using CNBr-activated Sepharose 4B. J. Clin. Chem. Clin. Biochem. 14, 475-478.

23. van Eijk, H. G. \& van Noort, W. L. (1992) The analysis of human serum transferrins with the Phast-System: Quantitation of microheterogeneity. Electrophoresis 13, 354-358.

24. van Eijk, H. G. \& van Noort, W. L. (1986) The reliability of the use of para toluene sulfonic acid for simultaneous hydrolysis and quantitation of both $\mathrm{N}$-acetylglucosamine and amino acids in human transferrins. Clin. Chim. Acta 157, 305-310.

25. van Noort, W. L. \& van Eijk, H. G. (1990) Quantification of Monosaccharides Occurring in Glycoproteins at Subnanomole levels Using an Automated LC Analyzer. LC-GC Intl. 3/5, $50-52$.

26. Turner, G. A. (1985) Relation between raised concentrations of fucose, sialic acid, and acute phase proteins in serum from patients with cancer: Choosing suitable serum glycoprotein markers. J. Clin. Pathol. 38, 588-592.

27. Kilar, F. \& Hjertén, S. (1989) Fast and high resolution analysis of human serum transferrin by high performance isoelectric focusing in capillaries. Electrophoresis 10, 23-29.

28. Feelders, R. A., Vreugdenhil, G., de Jong, G., Swaak, A. J. G. \& van Eijk, H. G. (1992) Transferrin microheterogeneity in rheumatoid arthritis. Rheumatol. Int. 12, 195-199.

29. Taverna, M., Baillet, A., Biou, D., Schlüter, M., Werner, R. \& Ferrier, D. (1992) Analysis of carbohydrate-mediated hetèrogeneity and characterization of $\mathrm{N}$-linked oligosaccharides of glycoproteins by high performance capillary electrophoresis. Electrophoresis $13,359-366$.

30. Nicolson, G. L. \& Irimura, T. (1984) Estimating glycoprotein carbohydrate chain structures by lectin reactivities in polyacrylamide gels. Biol. Cell. 51, 157-164.

31. Townsend, R. R., Hardy, M. R., Cumming, D. A., Carver, J. P. \& Bendiak, B. (1989) Separation of branched sialylated oligosaccharides using high-pH anion-exchange chromatography with pulsed amperometric detection. Anal. Biochem. 182, $1-8$.

32. Bezouska, K., Taborsky, O., Kubrycht, J., Pospisil, M. \& Kocourek, J. (1985) Carbohydrate-structure-dependent recognition of desialylated serum glycoproteins in the liver and leucocytes. Biochem. J. 227, 345-354.

33. MacGillivray, R. T. A., Mendez, E., Sinha, S. K., Sutton, M. R., Lineback-Zins, J. \& Brew, K. (1982) The complete amino acid sequence of human serum transferrin. Proc. Natl. Acad. USA $79,2504-2508$.

Prof. Dr. H. G. van Eijk

Erasmus University Rotterdam Department of Chemical Pathology

Room EE 600

P. O. Box 1738

NL-3000 DR Rotterdam

The Netherlands 